\title{
Caracterização comercial de raízes de cenoura de seis ciclos de seleção da variedade 'Londrina'
}

\author{
Commercial characterization of 'Londrina' carrot roots on \\ six cycles of selection
}

\author{
Cristina Batista de Lima ${ }^{1 *}$; João Carlos Athanázio ${ }^{2}$
}

\begin{abstract}
Resumo
A cenoura é uma espécie de clima ameno que após o advento de cultivares tolerantes ao calor, passou a ser cultivada, no Brasil, praticamente durante o ano todo. Entretanto, fatores como temperatura, umidade relativa do ar, fotoperíodo, época de colheita e preferência do mercado consumidor, devem ser observados na escolha da cultivar adequada a cada região e época de semeadura. Visando a obtenção de informações a respeito do material utilizado por produtores de cenoura do município de Londrina-PR, o presente trabalho teve por objetivo analisar parâmetros comerciais e de produção de raízes, de seis ciclos de seleção da variedade 'Londrina', comparando-as com a cultivar Brasília. O trabalho foi conduzido no campus da Universidade Estadual de Londrina (UEL), de fevereiro a junho de 2003. Foram realizadas três avaliações, analisando-se as características florescimento (\%), número de plantas $/ \mathrm{m}^{2}$, coloração, comprimento, diâmetro, formato, massa fresca e produtividade de raízes. O delineamento experimental foi o de blocos casualizados com sete tratamentos e cinco repetições. Os materiais obtidos a partir de seis ciclos de seleção da variedade de cenoura 'Londrina' produziram raízes com características comerciais (coloração, comprimento, diâmetro e formato), que atendem a exigência do mercado consumidor e assemelham-se às da cultivar Brasília, demonstrando ser um material com potencial promissor para ser lançado como cultivar no mercado nacional, indicado para regiões com características semelhantes as do local do estudo.
\end{abstract}

Palavras-chave: Daucus carota L., formato, produção, época de colheita, hortaliças

\begin{abstract}
Carrot is a crop for mild climate but after development of cultivars with heat tolerance, it is cultivate in Brazil during all year long. However, factors as: temperature, relative air humidity, photoperiod, harvest time and consumers preference must be observed at the moment of correct cultivar choice for each region and sowing season. This work was carried out to observe commercial parameters and root production from six selection cycles of Londrina cultivar, comparing them to Brasíla cultivar with the purpose of obtaining informations about the cultivars used by carrot growers in Londrina county-PR. The research was set up at the campus of Universidade Estadual de Londrina, since February till June, 2003. There evaluations were done about flowering characteristics (\%), coloration, length, diameter, shape, fresh mass and root yield. Experimental design was randomized blocks, with seven treatments and five replications. The plants obtained after six selection cycles of 'Londrina' carrot produced roots with commercial characteristics for coloring, length, diameter and shape, complying consumers demand, similar to that Brasília cultivar, showing to be a promising selectionl to introduce on national market as a cultivar, indicated for regions with similar local characteristics.
\end{abstract}

Key words: Daucus carota L., shape, production, harvest time, vegetables

1 Enga Agra ${ }^{\mathrm{a}}$ Dra Docente do Departamento de Produção Vegetal da Universidade Estadual do Norte do Paraná - Faculdades "Luiz Meneghel" (UENP-FALM); e-mail: crislima@ffalm.br.

2 Eng $^{\mathrm{o}}$ Agr $^{\circ}$, Dr. Prof ${ }^{\circ}$ do Centro de Ciências Agrárias da Universidade Estadual de Londrina (UEL), 86051-990, Londrina-PR.

* Autor para correspondência 


\section{Introdução}

A cenoura (Daucus carota L.) é uma importante fontede $\beta$-caroteno, precursorda vitaminaA, utilizada no combate a deficiência dessa substância. No Brasil destacam-se as regiões produtoras no Sudeste (MG e $\mathrm{SP})$, Sul (PR) e Nordeste (BA), com média nacional de $33 \mathrm{t} \mathrm{ha}^{-1}$ (FUNDAÇÃO NEWTON PAIVA CONSULTORIA \& AGROINFORMATIVOS, 2006). Segundo Camargo Filho e Alves (2005), a variação média do preço da cenoura comercializada na Companhia de Entrepostos e Armazéns Gerais de São Paulo (CEAGESP) nos últimos dez anos, é de $\mathrm{R} \$ 12,60$ nos anos ímpares e $\mathrm{R} \$ 12,85$ nos anos pares, para caixas de $25 \mathrm{~kg}$.

Trata-se de uma espécie de clima ameno que a pós o advento de cultivares tolerantes ao calor passou a ser cultivada, no Brasil, praticamente durante o ano todo. Entretanto, fatores como temperatura, umidade relativa do ar, fotoperíodo, época de colheita e preferência do mercado consumidor, devem ser observados na escolha da cultivar adequada a cada região e época de semeadura, a fim de se obter sucesso na exploração comercial de suas raízes (DUDA; REGHIN, 2000). Os altos valores de temperatura e umidade relativa, que normalmente ocorrem no verão favorecem o aparecimento dos patógenos Alternaria dauci, Cercospora carotae e Xanthomonas campestris $p v$. carotae, causadores da principal doença que afeta a cultura, a queima das folhas, propiciando a escassez do produto no mercado nessa época, com conseqüente elevação de preços (OLIVEIRA; BRAZ; BANZATTO, 2005).

$\mathrm{Na}$ tentativa de atender a demanda pelo produto ao longo do ano, o cultivo de cenoura tem sido realizado, com utilização de genótipos nacionais durante a primavera-verão e importados no período de outono-inverno (DUDA; REGHIN, 2000). Todavia, a diversidade de clima existente nas diferentes épocas e localidades de cultivo, pode interferir na adaptabilidade, estabilidade e, conseqüentemente, no desenvolvimento e produtividade dos genótipos utilizados.
Segundo Cruz e Castoldi (1991), existem respostas diferenciadas de genótipos às variações ambientais e estas, dificultam a recomendação de um ou mais cultivares para uma extensa faixa de ambientes, uma vez que essa indicação é feita com base nas médias de suas produtividades em vários locais, sem levar em consideração as situações específicas de cada região. Assim sendo, torna-se imprescindível à realização de pesquisas para se estabelecer genótipos melhor adaptados às diversas condições climáticas encontradas no Brasil. A falta de conhecimento do comportamento de diferentes cultivares de cenoura para cada época específica de semeadura tem dificultado melhor desempenho da cultura (REGHIN; DUDA, 2000).

Em Londrina-PR, os agricultores trabalham com uma variedade de cenoura denominada popularmente 'Londrina' que apresenta boa adaptação ao clima local e, características semelhantes as da cultivar Brasília. O processo de seleção e melhoramento desta população foi realizado de maneira empírica, e a semente é produzida para utilização própria. Sua semeadura ocorre em junho e julho de modo que, em setembro e outubro as plantas florescem induzidas por fotoperíodo longo. Aépoca de produção de raizé principalmente no outono e inverno. Essa variedade é descrita apenas no trabalho de Reghin et al. (1985) faltando, desse modo, informações científicas a respeito de suas características comerciais.

Visando a obtenção de informações a respeito do material utilizado por produtores de cenoura do município de Londrina-PR, o presente trabalho teve por objetivo analisar parâmetros comerciais e de produção de raízes, de seis ciclos de seleção da variedade 'Londrina', comparando-as com a cultivar Brasília.

\section{Material e Métodos}

O trabalho foi conduzido no campus da Universidade Estadual de Londrina (UEL) de fevereiro a junho de 2003. Londrina situa-se na 
região norte do Estado do Paraná, latitude $23^{\circ} 22^{\prime} \mathrm{S}$ e longitude $51^{\circ} 10^{\prime} \mathrm{W}$.

Em 1986 foram adquiridos lotes de sementes da variedade 'Londrina' junto a produtores da região. Essas sementes foram misturadas obtendo-se apenas um lote. Iniciou-se desde então um trabalho de seleção recorrente para características comerciais de raízes nessa variedade, no qual, a cada ano as sementes foram semeadas no mês de janeiro, as raízes produzidas colhidas em maio, analisadas, selecionadas e replantadas em junho, para posterior colheita de suas sementes. As sementes assim produzidas (sistema semente-raiz-semente) a cada ano foram colhidas, beneficiadas, acondicionadas em sacos de papel Kraft aluminizados e armazenadas individualmente em câmara fria $\left(10^{\circ} \mathrm{C}\right)$. No presente estudo utilizou-se sementes de seis ciclos dessa seleção produzidas nos anos de 1997, 1998, 1999, 2000, 2001 e 2002. As sementes da cultivar Brasília, utilizadas como testemunha, foram adquiridas no comércio local. A semeadura foi realizada em 12 de fevereiro de 2003.

O preparo do solo constituiu-se de aração e gradagem e os canteiros foram confeccionados, mediante emprego de enxada rotativa. A caracterização química do solo do local de instalação do experimento está descrita na Tabela 1 .

Tabela 1. Resultados das análises químicas da amostra de solo* do local de condução do experimento.

\begin{tabular}{cccccccccccc}
\hline $\begin{array}{c}\text { Profundidade } \\
(\mathrm{cm})\end{array}$ & $\begin{array}{c}\mathrm{pH} \\
\left(\mathrm{CaCl}_{2}\right)\end{array}$ & $\begin{array}{c}\mathrm{M} . \mathrm{O} . \\
\mathrm{g} / \mathrm{dm}^{3}\end{array}$ & $\begin{array}{c}\mathrm{P} \\
\left(\mathrm{mg} / \mathrm{dm}^{3}\right)\end{array}$ & $\mathrm{K}$ & $\mathrm{Ca}$ & $\mathrm{Mg}$ & $\mathrm{H}+\mathrm{Al}$ & $\mathrm{SB}$ & $\mathrm{CTC}$ & $\begin{array}{c}\text { Sat. por Bases } \\
\mathrm{V}(\%)\end{array}$ \\
\hline $0-20$ & & & & $--------------\mathrm{cmol}_{\mathrm{c}} / \mathrm{dm}^{3}-------------$ & & \\
& 4,7 & 18,8 & 10,5 & 0,35 & 5,4 & 1,2 & 4,8 & 6,9 & 11,7 & 59,3 \\
\hline
\end{tabular}

* Realizada no laboratório de Análise Química e Física do Solo da Universidade Estadual do Norte do Paraná Faculdades “Luiz Meneghel” (UENP-FALM), Bandeirantes-PR.

As condições climáticas durante o período de condução do trabalho, obtidas na estação meteorológica do Instituto Agronômico do Paraná (IAPAR) de Londrina-PR, estão descritas para temperatura e precipitação pluvial na Figura 1. A temperatura média nesse período foi de $21,6^{\circ} \mathrm{C}$ e a precipitação de $81,3 \mathrm{~mm}$.
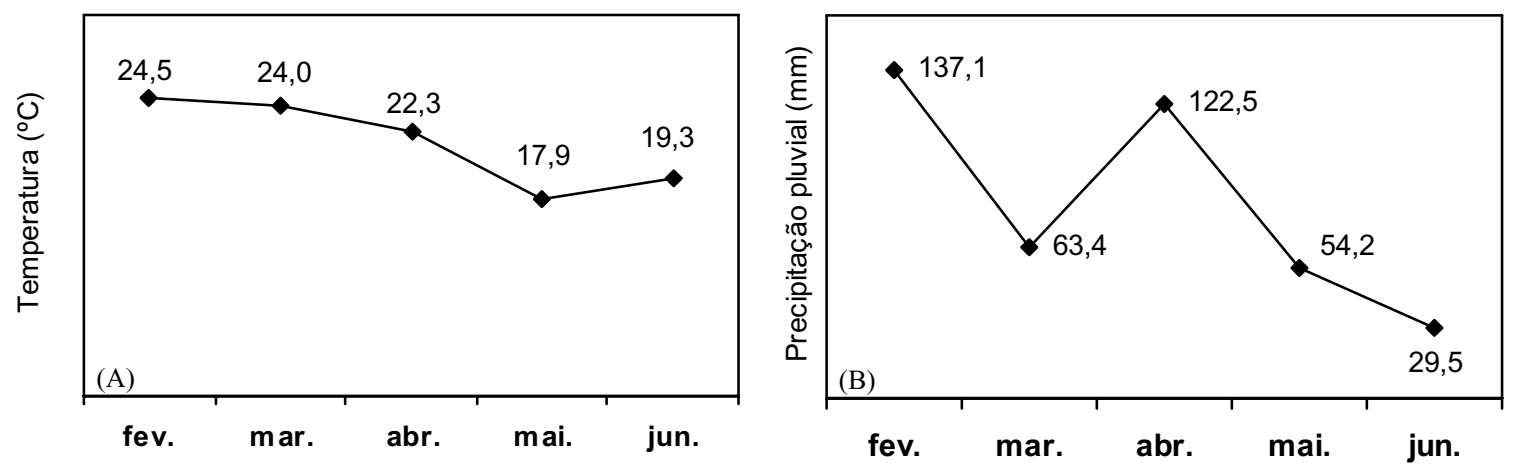

Figura 1. Médias de temperatura (A) e precipitação pluvial (B) no período de fevereiro a junho de 2003 no município de Londrina-PR. 
O delineamento experimental utilizado foi $\mathrm{o}$ de blocos casualizados contendo sete tratamentos (sementes obtidas de seis ciclos de seleção da variedade 'Londrina' e a cultivar Brasília) e cinco repetições, num total de trinta e cinco parcelas. As médias originais obtidas foram submetidas à análise de variância e comparadas pelo teste de Tukey, a $5 \%$ de probabilidade.

As parcelas constituíram-se de canteiros com 1,20 metros de largura, 3,0 metros de comprimento $\left(3,6 \mathrm{~m}^{2}\right)$ e 20 centímetros de altura. As sementes foram distribuídas nos canteiros em 5 linhas com aproximadamente $1 \mathrm{~cm}$ de profundidade. Por ocasião do raleio, realizado 25 dias após a semeadura, as plantas foram espaçadas deixando-se de 5 a 10 centímetros entre si.

De acordo com os resultados das análises químicas do solo, efetuou-se a correção do solo através da aplicação de 1,48 $\mathrm{t} \mathrm{ha}^{-1}$ de calcário, incorporado 60 dias antes da semeadura. Antecedendo em uma semana a data da semeadura foi feita a adubação mineral de plantio com $500 \mathrm{~kg} \mathrm{ha}^{-1}$ do formulado 4-14-8. A adubação de cobertura foi realizada com $80 \mathrm{~kg} \mathrm{ha}^{-1}$ de uréia, disponibilizada aos 25 e 40 dias após a semeadura. Para a adubação orgânica utilizou-se $20 \mathrm{t} \mathrm{ha}^{-1}$ de esterco bovino. Os demais tratos culturais usuais seguiram de acordo com as recomendações para o cultivo convencional dessa cultura, sem a aplicação de fungicida, para se averiguar a ocorrência de queima das folhas.

Foram realizadas três avaliações aos 100, 115 e 130 dias após a semeadura, nas quais, foram colhidas aleatoriamente, dez plantas por parcela sem indício de pendoamento. Essas plantas foram levadas ao laboratório para retirada da parte aérea e limpeza das raízes, que a seguir, foram analisadas quanto a coloração, comprimento, diâmetro, massa fresca, e formato. Avaliou-se também em cada época as características florescimento (\%) e produtividade de raízes.

Para verificação do formato, que normalmente é feita de maneira visual, utilizou-se uma fórmula matemática, com o objetivo de quantificar as variações existentes entre as raízes. Desse modo, a análise deixa de ser subjetiva, fazendo com que essa tarefa seja efetuada com precisão, diminuindo as possibilidades de interpretações equivocadas. O índice de formato (IF) foi estabelecido através da fórmula: $\mathrm{IF}=\mathrm{VR} / \mathrm{VI}$, onde $\mathrm{VR}=$ volume real e $\mathrm{VI}=$ volume ideal ${ }^{3}$. O volume real foi verificado com o auxílio de uma proveta graduada de $1000 \mathrm{~mL}$. Para cada raiz, a proveta foi cheia de água (volume inicial), a seguir a raiz foi imersa e retirada da proveta medindo-se o volume que nela permaneceu. O volume real foi obtido subtraindo-se do volume inicial, o que restou na proveta. $\mathrm{O}$ volume ideal foi estimado através da fórmula do cilindro sendo que, o valor obtido para índice de formato próximo a 1 indica formato cilíndrico e próximo a 0,5 formato cônico.

As raízes foram pesadas em balança digital, o comprimento foi estabelecido em centímetros, medindo-se do ombro até o ápice e o diâmetro verificado através de paquímetro, na região de maior largura. Para a característica produtividade, o peso médio de 10 raízes obtido por parcela em cada avaliação foi estimado em toneladas por hectare $(\mathrm{t}$ ha $^{-1}$ ) de área ocupada.

\section{Resultados e Discussão}

Os percentuais médios de florescimento em plantas de cenoura de seis ciclos de seleção da variedade 'Londrina', estão apresentados na Figura 2. Os materiais avaliados apresentaram percentual de florescimento superior ao da cultivar Brasília, e variaram entre si $6,5 \%$. Essa divergência, provavelmente se deve ao fato de não ter sido efetuada uma pressão de seleção das raízes analisadas em cada ciclo, para diminuição dessa característica na variedade estudada. Nota-se, todavia, uma tendência de estabilização desse percentual nos anos de 2001

\footnotetext{
Sugestão do Prof. João Carlos Athanázio na disciplina de melhoramento genético de hortaliças do curso de pósgraduação em Agronomia da UEL, no $2^{\circ}$ semestre de 2002.
} 
e 2002. O baixo pendoamento da cultivar Brasília está de acordo com o relatado por Nicoulaud, Porto e Matsumura (1997), onde não se observou florescimento prematuro para essa cultivar, em semeaduras realizadas no mês de fevereiro. Segundo
Reghin e Duda (2000) Brasília apresentou 20,7\% de florescimento prematuro quando semeada em setembro. A média geral para florescimento obtida nos ciclos de seleção 'Londrina' não comprometeu sua produtividade de raízes.

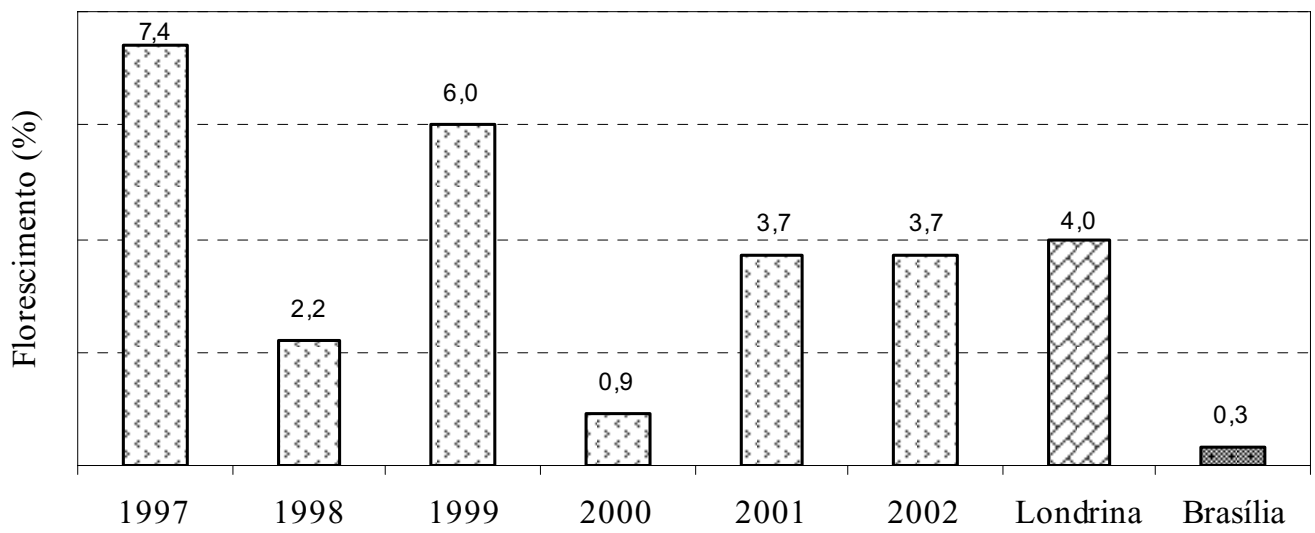

Figura 2. Médias de florescimento em porcentagem de diferentes ciclos de seleção de cenoura 'Londrina' e da cultivar Brasília.

Não se verificou a ocorrência de queima das folhas, o que sugere, certa tolerância dos materiais analisados aos agentes causadores dessa doença, uma vez que as condições climáticas durante a condução do experimento foram favoráveis ao desenvolvimento desses patógenos. Segundo Reis e Vieira (2006) as cultivares nacionais desenvolvidas para plantio no verão apresentam maior resistência a queima das folhas do que as de inverno, entretanto, essa resistência pode variar em função do nível de severidade da doença e tempo de predominância desses microrganismos na região de cultivo.

As médias observadas para comprimento e diâmetro das raízes de cenoura, em cada época de colheita estão apresentadas na Tabela 2.

Tabela 2. Comprimento e diâmetro $(\mathrm{cm})$ médios de raízes de diferentes ciclos de seleção de cenoura 'Londrina' e da cultivar Brasília, obtidos em três épocas de colheita.

\begin{tabular}{|c|c|c|c|c|c|c|}
\hline \multirow{3}{*}{ Ciclos de seleção } & \multicolumn{3}{|c|}{ Comprimento $(\mathrm{cm})$} & \multicolumn{3}{|c|}{ Diâmetro $(\mathrm{cm})$} \\
\hline & \multicolumn{6}{|c|}{ Épocas de colheita (dias após semeadura) } \\
\hline & 100 & 115 & 130 & 100 & 115 & 130 \\
\hline 1997 & $19,1 \mathrm{ABa}^{1}$ & $18,9 \mathrm{Aa}$ & $19,4 \mathrm{Aa}$ & $3,8 \mathrm{Ab}$ & $4,0 \mathrm{Aab}$ & $4,3 \mathrm{Aa}$ \\
\hline 1998 & $18,3 \mathrm{ABb}$ & $20,0 \mathrm{Aab}$ & $20,4 \mathrm{Aa}$ & 3,9 Aa & $3,9 \mathrm{Aa}$ & $4,1 \mathrm{Aa}$ \\
\hline 1999 & $19,2 \mathrm{ABa}$ & $19,3 \mathrm{Aa}$ & $19,2 \mathrm{Aa}$ & $3,7 \mathrm{Aa}$ & $3,8 \mathrm{Aa}$ & $4,0 \mathrm{Aa}$ \\
\hline 2000 & $19,5 \mathrm{Aa}$ & $19,8 \mathrm{Aa}$ & $19,7 \mathrm{Aa}$ & $3,7 \mathrm{Aa}$ & $3,8 \mathrm{Aa}$ & $4,1 \mathrm{Aa}$ \\
\hline 2001 & $18,1 \mathrm{ABb}$ & $18,9 \mathrm{Aab}$ & $20,2 \mathrm{Aa}$ & $3,7 \mathrm{Ab}$ & 3,9 Aab & 4,3 Aa \\
\hline 2002 & $18,5 \mathrm{ABa}$ & $18,9 \mathrm{Aa}$ & $19,7 \mathrm{Aa}$ & $3,8 \mathrm{Ab}$ & 4,2 Aab & $4,6 \mathrm{Aa}$ \\
\hline Brasília & $16,9 \mathrm{Ba}$ & $17,8 \mathrm{Aa}$ & $18,3 \mathrm{Aa}$ & 3,9 Aa & 4,2 Aa & 4,4 Aa \\
\hline Londrina & 18,8 & 19,3 & 19,8 & 3,8 & 3,9 & 4,2 \\
\hline $\mathrm{CV} \%$ & \multicolumn{3}{|c|}{6,5} & \multicolumn{3}{|c|}{9,1} \\
\hline
\end{tabular}

${ }^{1}$ Médias seguidas pela mesma letra maiúscula na coluna e minúscula na linha, não diferem entre si pelo teste de Tukey a $5 \%$ de probabilidade. $\mathrm{CV}=$ Coeficiente de variação. 
Para comprimento, verificou-se diferença entre as raízes apenas na primeira avaliação, onde o ciclo de seleção da variedade 'Londrina' colhido no ano 2000 apresentou médias significativamente superiores as da cultivar Brasília, apesar de ambas estarem dentro da faixa padrão de comercialização. Resultado semelhante, para Brasília foi observado por Oliveira, Braz e Banzatto (2004). As raízes variaram de 16,9 a $20,4 \mathrm{~cm}$ de comprimento e na média, superaram a testemunha nas três épocas de colheita. Brasília manteve-se dentro da faixa comercial nas três épocas concordando com o relatado por Bonin e Souza (1990), de que essa cultivar produz raízes em torno de $18 \mathrm{~cm}$.
Os diâmetros das raízes dos ciclos de seleção de cenoura analisados não diferiram entre as populações em nenhuma das avaliações. As raízes dos anos 1997, 2001 e 2002 apresentaram na terceira época de colheita, os maiores diâmetros provavelmente, devido a maior permanência das plantas no campo. Contudo, na média, os diâmetros foram semelhantes aos da testemunha em todas as avaliações.

As médias referentes a índice de formato e massa fresca de raízes estão apresentadas na Tabela 3. Para ambas as características, não foram verificadas diferenças significativas entre os materiais estudados em nenhuma das avaliações.

Tabela 3. Médias de índice de formato e massa fresca $(\mathrm{g})$ de raízes de diferentes ciclos de seleção de cenoura 'Londrina' e da cultivar Brasília, obtidas em três épocas de colheita.

\begin{tabular}{|c|c|c|c|c|c|c|}
\hline \multirow{3}{*}{ Ciclos de seleção } & \multicolumn{3}{|c|}{ Índice de Formato } & \multicolumn{3}{|c|}{ Massa (g) } \\
\hline & \multicolumn{6}{|c|}{ Épocas de colheita (Dias após semeadura) } \\
\hline & 100 & 115 & 130 & 100 & 115 & 130 \\
\hline 1997 & $0,67 \mathrm{Aa}^{1}$ & $0,72 \mathrm{Aa}$ & $0,74 \mathrm{Aa}$ & $148,7 \mathrm{Ab}$ & $170,5 \mathrm{Aab}$ & $212,5 \mathrm{Aa}$ \\
\hline 1998 & $0,68 \mathrm{Aa}$ & $0,72 \mathrm{Aa}$ & $0,72 \mathrm{Aa}$ & $155,7 \mathrm{Aa}$ & $174,9 \mathrm{Aa}$ & $197,3 \mathrm{Aa}$ \\
\hline 1999 & $0,68 \mathrm{Aa}$ & $0,77 \mathrm{Aa}$ & $0,78 \mathrm{Aa}$ & $148,3 \mathrm{Aa}$ & $157,3 \mathrm{Aa}$ & $181,5 \mathrm{Aa}$ \\
\hline 2000 & $0,65 \mathrm{Ab}$ & $0,78 \mathrm{Aa}$ & $0,75 \mathrm{Aab}$ & $146,8 \mathrm{Aa}$ & $166,2 \mathrm{Aa}$ & $193,0 \mathrm{Aa}$ \\
\hline 2001 & $0,71 \mathrm{Aa}$ & $0,74 \mathrm{Aa}$ & $0,70 \mathrm{Aa}$ & $138,1 \mathrm{Ab}$ & $169,9 \mathrm{Aab}$ & $211,7 \mathrm{Aa}$ \\
\hline 2002 & $0,64 \mathrm{Ab}$ & $0,75 \mathrm{Aa}$ & 0,70 Aab & $145,7 \mathrm{Ab}$ & $185,4 \mathrm{Aab}$ & $229,4 \mathrm{Aa}$ \\
\hline Brasília & $0,67 \mathrm{Aa}$ & $0,74 \mathrm{Aa}$ & 0,70 Aa & $148,3 \mathrm{Ab}$ & $173,3 \mathrm{Aab}$ & $196,4 \mathrm{Aa}$ \\
\hline Londrina & 0,67 & 0,75 & 0,73 & 147,2 & 170,7 & 204,2 \\
\hline $\mathrm{CV} \%$ & \multicolumn{3}{|c|}{9,1} & \multicolumn{3}{|c|}{18,0} \\
\hline
\end{tabular}

${ }^{1}$ Médias seguidas pela mesma letra maiúscula na coluna e minúscula na linha, não diferem entre si pelo teste de Tukey a $5 \%$ de probabilidade. $\mathrm{CV}=$ Coeficiente de variação.

Quanto ao formato, apenas as seleções colhidas nos anos 2000 e 2002 diferiram entre as avaliações, observando-se na segunda época, maior proporção de raízes cilíndricas, coincidindo com o relatado por Pereira et al. (1996), quando afirmam que colheitas realizadas neste período fornecem raízes com melhor qualidade comercial e, conseqüentemente, maiores expectativas de lucro. As raízes de cenoura 'Londrina' apresentaram formato cilíndrico, semelhantes as da cultivar Brasília. O método utilizado para se verificar o formato das raízes estudadas, demonstrou-se preciso, rápido e de fácil execução podendo ser empregado em ensaios que visem a qualidade comercial ou melhoramento de raízes de cenoura.

A massa fresca de raízes dos ciclos colhidos nos anos de 1997, 2001, 2002 e a cultivar Brasília diferiram entre as épocas de colheita, de modo que as raízes colhidas aos 100 dias após a semeadura foram consideradas adequadas a comercialização. Pereira et al. (1996) comentam que essa época favorece a obtenção de raízes leves e tenras, agradando os consumidores de mercados exigentes nesse quesito. 
Considerando-se todos os parâmetros envolvidos para se determinar a época de colheita propícia para aquisição de raízes de cenoura, com qualidade e rentabilidade, pode-se inferir que as raízes da variedade 'Londrina' devem ser colhidas entre 100 e 115 dias após a semeadura.

No tocante a produtividade (Figura 3) a população 2002 apresentou a maior média numérica superando a cultivar Brasília em 3,5 t ha-1. A produtividade das populações estudadas superou as médias mundial e nacional. Resende, Vieira e Vidal (2005), observaram resultados semelhantes no que se refere a cultivar Brasília em seus trabalhos. Entretanto, esses resultados são inferiores aos relatados por Oliveira, Braz e Banzatto (2005), enquanto que, Schuch, Soares e Schuck (1999) em Porto AlegreRS, observaram uma produtividade de $26,7 \mathrm{tha}^{-1}$ para a referida cultivar.

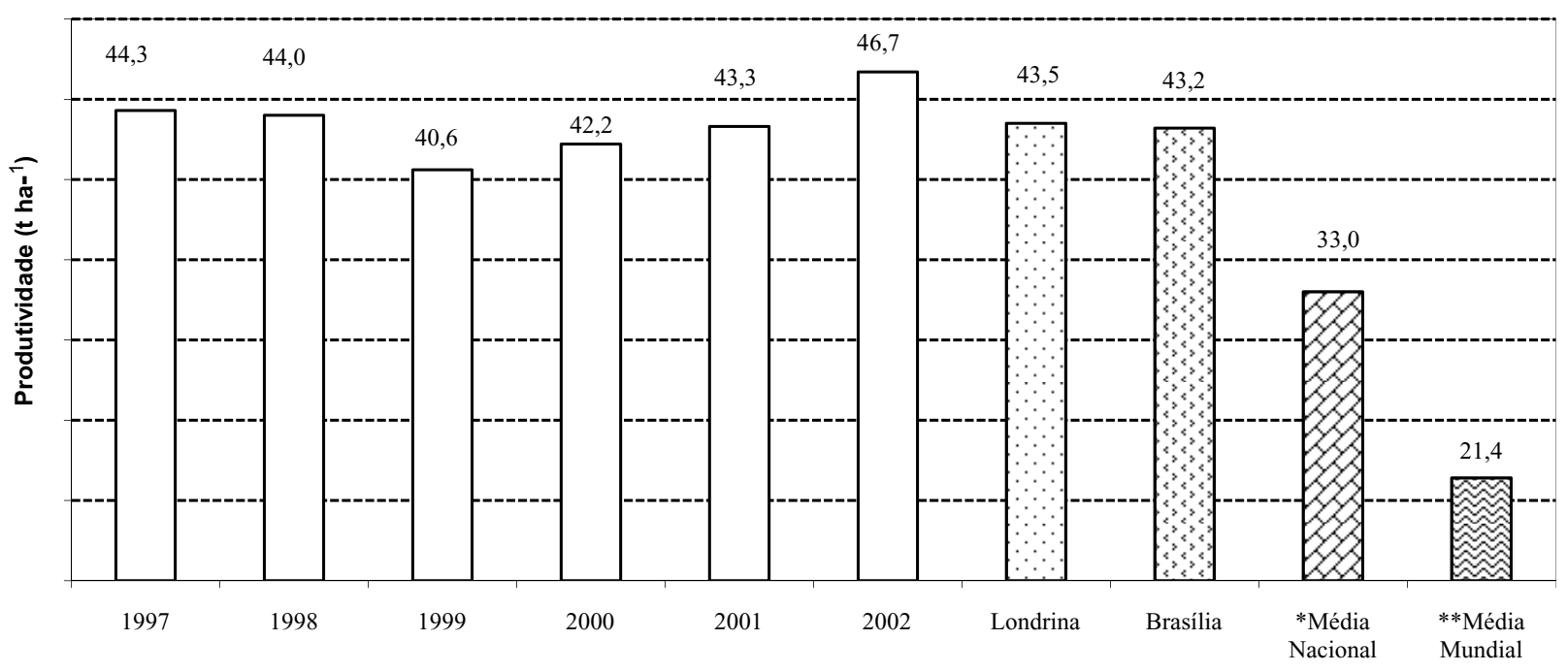

Figura 3. Produtividade $\left(\mathrm{t} \mathrm{ha}^{-1}\right)$ de raízes de diferentes ciclos de seleção de cenoura 'Londrina' e da cultivar Brasília. Londrina - PR, 2006. * Fundação Newton Paiva Consultoria \& Agroinformativos (2006); ** Food and Agriculture Organization - FAO, 2004.

As raízes de cenoura produzidas pelas plantas, obtidas a partir de sementes de seis ciclos de seleção da variedade 'Londrina', atenderam a exigência do mercado consumidor, que de acordo com Vieira, Pessoa e Makishima (1997), preferem raízes cilíndricas, lisas, sem raízes laterais ou secundárias, uniformes, com 15 a $20 \mathrm{~cm}$ comprimento e 3 a 4 $\mathrm{cm}$ diâmetro. A coloração deve ser alaranjada intensa, sem pigmentação verde ou roxa, na parte superior das raízes. O comportamento dos ciclos de seleção estudados indica que essa variedade está em equilíbrio, portanto, as médias tendem a se repetir em diferentes locais que apresentem condições climáticas, semelhantes as observadas no presente trabalho.
Além disso, sua produtividade na média geral dos ciclos de seleção, superou em $300 \mathrm{~kg}$ a cultivar Brasília, com possibilidade de aumento desse valor para até 3,5 toneladas, observado na seleção de 2002. Este fato é relevante para os produtores de cenoura da região, pois, com maior produtividade aliada à qualidade de raízes, eles podem incrementar sua renda familiar em torno de $\mathrm{R} \$ 1.799,00$ ha ${ }^{-1}$, considerando o preço médio de $\mathrm{R} \$ 12,85$ por caixa de $25 \mathrm{~kg}$ relatado por Camargo Filho e Alves (2005).

\section{Conclusões}

Os materiais obtidos a partir de seis ciclos de seleção da variedade de cenoura 'Londrina' 
produziram raízes com características comerciais (coloração, comprimento, diâmetro e formato), que atendem a exigência do mercado consumidor e assemelham-se às da cultivar Brasília, demonstrando ser um material com potencial promissor para ser lançado como cultivar no mercado nacional, indicado para regiões com características semelhantes as do local do estudo.

A produtividade média obtida foi de $43,5 \mathrm{t}$ $\mathrm{ha}^{-1}, 10,5 \mathrm{t}$ acima da média nacional, 22,1 $\mathrm{t}$ acima da média mundial e $300 \mathrm{~kg}$ acima da média da cultivar Brasília. A variedade de cenoura 'Londrina' apresenta-se como boa fonte de renda para os pequenos produtores de hortaliças da região de Londrina-PR.

\section{Referências}

BONIN, V.; SOUZA, Z. S. Avaliação de cultivares de cenoura nas semeaduras de primavera no Vale do Rio Canoas, SC. Agropecuária Catarinense, Florianópolis, v. 3, n. 4, p. 39-41, dez. 1990.

CAMARGO FILHO, W. P.; ALVES, H. S. Mercado de cenoura no Brasil: contribuições da pesquisa, alterações na produção e na estacionalidade. Horticultura Brasileira, Brasília, v. 23, n. 2, ago. 2005. Suplemento 2. CDROM.

CRUZ, C. D.; CASTOLDI, F. L. Decomposição da interação genótipos $\mathrm{x}$ ambientes em partes simples e complexa. Revista Ceres, Viçosa, v. 38, n. 219, p. 422430, 1991.

DUDA, C.; REGHIN, M. Y. Efeito da época de semeadura em cultivares de cenoura. In: ENCONTRO DE INICIAÇÃO CIENTÍFICA, 4., 2000, São José dos Campos. Anais... São José dos Campos: Universidade do Vale do Paraíba, 2000. p. 47.

FOOD AND AGRICULTURE ORGANIZATION FAO. Production yearbook 2003. New York: FAO, 2004. v. 57.

FUNDAÇÃO NEWTON PAIVA CONSULTORIA \& AGROINFORMATIVOS. Agrianual 2006: anuário da agricultura brasileira. São Paulo: FNP Consultoria \& Agroinformativos, 2006.
NICOULAUD, B. A. L.; PORTO, M. D. M.; MATSUMURA, A. Desempenho de cultivares de cenoura durante duas épocas de produção no sul do Brasil. Horticultura Brasileira, Brasília, v. 15, n. 1, p. 25-27, maio, 1997.

OLIVEIRA, C. D.; BRAZ, L. T.; BANZATTO, D. A. Adaptabilidade e estabilidade fenotípica de genótipos de cenoura. Horticultura Brasileira, Brasília, v. 23, n. 3, p. 743-748, jul./set. 2005.

Comprimento, diâmetro, formato e textura de raízes de cenoura, cultivadas em diferentes locais. Horticultura Brasileira, Brasília, v. 22, n. 2, jul. 2004. Suplemento 2. CDROM.

PEREIRA, A. L.; PARRAGA, M. S.; CORRÊA, E. H. S. F.; OLIVEIRA, E. R. Efeito do estádio de colheita na cultura da cenoura (Daucus carota L.) I. nos componentes de rendimento. Revista Universidade Rural: Série Ciências da Vida, Itaguai, v. 17, n. 2, p. 19-23, 1996.

REGHIN, M. Y.; DUDA, C. Efeito da época de semeadura em cultivares de cenoura. Publicatio UEPG: Ciências Exatas e da Terra, Ciências Agrárias e Engenharias, Ponta Grossa, v. 6, n. 1, p. 103-114, 2000.

REGHIN, M. Y.; TASHIMA, H.; BALAN, C. C. B.; TRECENTI, R. Produção de sementes de cenoura (Dacus carota L.) pelo sistema semente a semente. Poliagro, Bandeirantes, v. 7, n. 1, p. 65-69, 1985.

REIS, A.; VIEIRA, J. V. Reação de cultivares comerciais de cenoura quanto à resistência à queima das folhas. Horticultura Brasileira, Brasília, v. 24, n. 1, jul. 2006, Suplemento 2. CDROM.

RESENDE, F. V.; VIEIRA, J. V.; VIDAL, M. C. Avaliação de populações de cenoura do programa de melhoramento da Embrapa Hortaliças em sistema orgânico de produção. Horticultura Brasileira, Brasília, v. 23, n. 2, ago. 2005. Suplemento 2. CDROM.

SCHUCH, S. M. L.; SOARES, M. H. G.; SCHUCK, E. Avaliação de cultivares de cenoura sob duas fontes de adubo orgânico animal na região da grande Porto Alegre, Rio Grande do Sul. Pesquisa Agropecuária Gaúcha, Porto Alegre, v. 5, n. 2, p. 193-200, 1999.

VIEIRA, J. V.; PESSOA, H. B. S. V.; MAKISHIMA, N. Cultivo da cenoura (Daucus carota L.). Brasília: EMBRAPA/CNPH, 1997. (Instruções técnicas da EMBRAPA Hortaliças, 13). 